\title{
SPILANTHES ACMELLA AND ITS MEDICINAL USES - A REVIEW
}

\author{
YASODHA PURUSHOTHAMAN ${ }^{1}$, SILAMBARASAN GUNASEELAN ${ }^{1}$, SUDARSHANA DEEPA VIJAYAKUMAR ${ }^{2 *}$
}

${ }^{1}$ Department of Biotechnology, Bannari Amman Institute of Technology, Erode, Tamil Nadu, India. ${ }^{2}$ Department of Biotechnology, NanoBiotranslational Research Laboratory, Bannari Amman Institute of Technology, Erode, Tamil Nadu, India. E-mail: sudarshanadeepav@ bitsathy.ac.in

Received: 10 January 2018, Revised and Accepted: 05 March 2018

\begin{abstract}
In common plant life has been recognized to alleviate various diseases. Spilanthes acmella- a vital native medicinal plant is also found in subcontinent of the united states of America. A range of abstracts and active metabolites from different parts of this plant had been found to contain valuable pharmacological activities. Conventionally recognized as toothache plant, it was known to suppress the ailment allied with toothaches and also found to stimulate saliva secretion. On survey of literature, it has been projected that it has numerous drug-related actions, which comprises of antimicrobial, antipyretic, local anesthetic, bioinsecticide against insects of agricultural importance, antioxidant, analgesic, antimicrobial, vasorelaxant, anti-human immune deficit virus, toothache relief and anti-inflammatory effects. Based on the traditional claims against a range of diseases, researchers have classified and estimated plants for their bioactive compounds. However, researchers found it to be a difficult task for the extraction of bioactive constituents from these plants. Therefore, the scientific information about $S$. acmella could be obtained from this current review.
\end{abstract}

Keywords: Spilanthes acmella, Toothache plant, Antifungal, Antipyretic, Local anesthetic, Bioinsecticide, Antioxidant, Analgesic, Antimicrobial, Vasorelaxant, Anti-inflammatory effects.

(C) 2018 The Authors. Published by Innovare Academic Sciences Pvt Ltd. This is an open access article under the CC BY license (http://creativecommons. org/licenses/by/4. 0/) DOI: http://dx.doi.org/10.22159/ajpcr.2018.v11i6.24697

\section{INTRODUCTION}

The haphazard usage of chemical pesticides to control pests has risen serious environmental pollutions, genetic resistance by pests and toxic residues in stored products, etc. Therefore, to reduce the detrimental effects of chemical pesticides on the environment, it is necessary to develop botanical pesticides which would be effective, relatively biodegradable and intended to provide broad-spectrum of activity [1]. Due to dynamic pharmacological potential and high levels of therapeutic value, there is a rising demand for herbal medicines and their increased recognition in the international markets which is considered to be a boon to the people. Conversely, struggles were done to standardize, explore and validate the ayurvedic medicines for their reliable potency, safety, and efficacy to bring them to market as core line therapeutics. For years plant related products from a varied variety of sources had been acknowledged and developed after having screened different plant species.

The Asteraceae which is known to be one of the largest vascular plant families, with an overall 30,000 species and 1100 genera, almost whole of these plant types were intended to display antimicrobial activity [43] which was due to the production of principal secondary metabolites, namely sesquiterpene [1]. The well-known genus Spilanthes had been found to contain 35 tropical species, of which three of them are reported from India. Probably around the world in tropical and subtropical regions Spilanthes acmella, a vital medicinal plant is prominently distributed. A wide range of therapeutics and medicinal constituents are present in this species [5]. The major constituents of this species such as "Spilanthol" and "Acmellonate," were at times used to reduce the pain related ailments such as a toothache and can potentially stimulate saliva secretion $[1,2]$. Some other traditional applications of this herb are as follows: $S$. acmella is well accepted for its intended use as spices, as an antiseptic agent, antimalarial, antibacterial, antifungal treatment, and as a remedy for toothache, flu, cough, rabies diseases, and tuberculosis [2,4].

\section{TRADITIONAL USES}

S. acmella is a widespread plant variety amongst the ancient tribal community; special food item is prepared during religious festival using this plant [3]. This plant is known to be a best remedial agent for toothache, throat and gum infections [6]. It is believed to be helpful in cases of tuberculosis [4]. Irula- tribal community people belonging to hasanur hills in the district of Erode - Tamil Nadu, call it by the local name "Mandal Poo Chedi" [7]. They have used the crushed flowers of this plant to apply at the site of toothache. Apart from Tamil Nadu, people from Betul and Chindwara district of Madhya Pradesh used the root paste of this plant for throat related ailmnets [8]. It had been known for its usage to relieve toothache (Sudan), for stomatitis (Java), and to heal the wound (India) [9]. In India, S. acmella, its flower heads were typically applied to treat and cure stammering in children. Presumably to treat leucorrhoea- a disease condition due to estrogen imbalance in females from Bangladesh tribal community, Spilanthes plant leaves, and flowers are prominently used [9]. This plant is also employed as a remedial agent for snake bite and in articular rheumatism treatment, in Cameroon regions [10]. On the other hand, this entire plant was used as "poisonous sting," especially in Chittagong hills-Bangladesh and also known by its other name Jhummosak [11].

\section{PHYTOCHEMISTRY}

The chemistry and pharmacology of any medicinal plant are related only when the phytochemical constituents of the specific plant are explored. Numerous parameters have been studied for the structural determination and chemical analysis of S. acmella and to determine its pungent alkamides. The fundamental pungent constituent reported from this plant S. acemella is the familiar "Spilanthol," an isobutylamide which is popular for its insecticidal properties [12,13]. Spilanthol was found to show $95-100 \%$ transience (mortality) against the $2^{\text {nd }}$ instar stage larvae of Plutella xylostella when it was compared to the crude extracts of methanol (60\%-70\%) and hexane (70-80) nearly after $48 \mathrm{~h}$ 
of exposure. The extracts from this plant $S$. acmella, was predominantly acknowledged for toxicity toward varied mosquito species such as Anopheles, Culex and Aedes. Prosperous source of vital constituents and principles could be obtained from the flower heads and root parts of this plant. A range of Triterpenoids is also one among the important compounds [14]. In general, Spilanthol is N-isobutylamide from chemistry aspects which had been found to be pungent in flavor and had capabilities to stimulate salivation. (2E, 6Z, 8E)-N-isobutylamide2,6,8-decatrienamid is the molecular formula determined for Spilanthol [15]. Spilanthol possess powerful bitter savor; it was also expected to produce general local astringency and anesthetic effects. Certain secondary metabolites have also been found to be contained in S. acmella. Spilanthol when concentrated by ethanolic method had been found to include $\mathrm{N}$-alkylamides at a total of $9.04 \%$ and $88.84 \%$ of spilanthol [16].

\section{PHARMACOLOGICAL ACTIONS}

The numerous pharmacological actions of $S$. acmella have been reviewed in Table 1.

\section{Local anesthetic activity}

Different animal models had been used for the estimation of the local anesthetic act of $S$. acmella:

Nupercaine was used as a standard to produce intracutaneous wheals in guinea pigs (appropriate to determine the measure of anesthesia) and Cocaine was used as a standard to produce plexus anesthesia in frog (employed to determine inception of anesthesia).

The local anesthetic action which was very effective, may perhaps attribute to the presence of alkylamides in S. acmella [17].

\section{Antipyretic effects}

S. acmella was evaluated by yeast induced methods, a general method used for the induction of pyrexia [18]. Inhibiting properties of lipooxygenase and cyclo-oxygenase were due to the presence of flavonoids had been suggested by reports [19]. Numerous studies were carried over differing doses of yeast which resulted in varied quantities of flavonoids extracted [19].

\section{Anti-inflammatory/analgesic activity}

Various studies had reported the anti-inflammatory properties of S. acmella on carrageenan, an inducer of hind paw disorder and a standard phlogistic agent to study anti-inflammatory activity [20]. Reports suggested significant dose-dependent inhibition of paw oedema. The results obtained indicated the extracts to be less efficient as to the standard drug mentioned by the researchers earlier. Researchers have also reported the presence of analgesic properties when coupled with acetic acid and have confirmed to induce abdominal constriction as revealed by a popular methodology, namely tail flick method. The results obtained with these plant extracts proved to be more efficient and effective as to tail flick method thus could be explored as peripherally acting analgesic [20]. The presence of flavonoids was found to be the powerful inhibitors of prostaglandins which were effective at the later stages of acute inflammation [20].

\section{Antifungal activity}

Aspergillus parasiticus, Aspergillus niger, Fusarium moniliformi and Fusarium oxysporum were the four different fungal species against which S. acmella had been active, which was demonstrated using flower head extracts of different concentrations [21]. Every concentration of the test solution was found to inhibit at varying degrees of sensitivity against the fungal species.

\section{Vasorelaxant and antioxidant activity}

Through partial endothelium induced nitric oxide and prostaglandin-I2 in a dose-dependent mode, the plant extracts were able to elicit vasorelaxation activity. Significantly, instantaneous vasorelaxation activity in nanogram levels was exhibited by the ethyl acetate extract of S.acmella, since it is the most potent antioxidant in the diphenyl picryl hydrazine assay (DPPH assay). On the other hand, highest vasorelaxation activity with the highest antioxidant concentration was produced by chloroform extracts $[24,25]$. It was due to the presence of tannins, flavonoids and phenolic compounds [26-28], the leaf extracts of $S$. acmella showed antioxidant potentiality as reported by the researches.

\section{Bioinsecticide and convulsant activity}

About 42 known species had been reported for the genus Spilanthes. Spilanthes alba, Spilanthes mauritiana, Spilanthes mauritiana oleracea, Spilanthes mauritiana ocymifolia, and S. acmella were found to consist of several insecticidal compounds $[2,12,32]$. Epilepsy in rats was induced by the hexanic extract of $S$. acmella when the characteristic electrographic seizures in the electroencephalogram were accompanied [25].

\section{TOXICOLOGY}

\section{Insecticidal toxicity of spilanthol}

The extract from the flower heads of $S$. acmella which contained spilanthol had been an active compound against Plutellaxylostella [36]. Aedes, Anopheles and Culex are the mosquito species that could be inhibited by the extracts from S. acmella. Usually, Spilanthol and alkylamides were known to attribute for the insecticidal properties [29].

Ovicidal, pupacidal, and insecticidal activities of the ethanolic extract from $S$. acmella were estimated at a dose of $7.5 \mathrm{ppm}$ concentration against Culex, Anopheles, and Aedesmosquito[37]. The hexane extract of dried flower buds of $S$. acmella, especially was found to be active against Aedesaegypti larvae as mentioned earlier. The spilanthol extract is a potent toxic compound against adults of Periplaneta americana. It is one of the most potent compounds when compared to conventional insecticides such as carbaryl, lindane, and bioresmethrin with a potency found to be 1.3, 3.8, and 2.6 times, respectively [36].

\section{Plant extraction procedure}

The plant extraction common techniques are basically maceration, infusion, percolation, digestion, decoction, aqueous-alcoholic extraction by fermentation, countercurrent extraction, microwaveassisted extraction, phytonic extraction (with hydrofluorocarbon solvents), ultrasound extraction (sonication), hot continuous extraction (Soxhlet), supercritical fluid extraction, and distillation techniques (water distillation, steam distillation [35].

Solid phase microextraction, protoplast based extraction, headspace trapping, and micro distillation are the few most recent extraction methods employed for the aromatic plants.

Certain parameters are possibly known to influence the extractquality, they are:

- Starting material obtained from a plant's part.

- Extraction procedure.

- Choice of solvent used for extraction.

Plant phytochemical effects tend to depend on [33,34]:

- Plant material environment.

- Its origin.

- Moisture content.

- Degree of processing

- Particle size.

Typical extraction methods employed can significantly affect the quality and sometimes the concentration of a secondary metabolite of an extract which depends on:

- Extraction type.

- Extraction time.

- Temperature.

- Solvent nature.

- Solvent concentration.

- Solvent polarity. 


\section{Plant components}

Any portion of the plant such as stem, bark, flowers, leaves, roots, fruits, and seeds can produce plant-based natural elements (Table 2).

\section{EXTRACTION PROCEDURES}

\section{Plant tissue homogenization}

In this technique the, plant parts either wet or dried were subjected to grinding with the aid of a blender to produce fine particles. These were then added with a suitable quantity of solvent and shaken vigorously either for 5-10 min or left for $24 \mathrm{~h}$, which was then filtered. To estimate the concentration, the filtrate may be dried under reduced pressure and then redissolved in a solvent. If clarification of the extract is required, the filtrate can be centrifuged [39].

\section{Soxhlet extraction}

There are possibilities for the desired compound to be partially soluble in a solvent. To overcome these difficulties, soxhlet extraction can be done which can even solubilize the impurities in the chosen solvent. The desired compound can be separated from the solvent containing insoluble substances using simple filtration techniques with filtration aids [38]. This is possible only if the compound has a high degree of solubility. The advantage of this technique relies on a single batch of solvent being recycled though a large portion of solvent gets passed through the sample. This method was not intended to be used on thermolabile compounds, as prolonged heating might result in the degradation of compounds [40].

\section{Maceration}

It is a process when the plant component is wholly or coarsely powdered after drying and allowed to be in contact with a solvent. This mixture is taken in a stoppered container which is frequently agitated for certain periods of time the compound is completely dissolved. This technique is reliable for thermolabile drug components [41].

\section{Decoction}

The crude drug containing heat stable and water-soluble components can be extracted when boiled in water for $15 \mathrm{~min}$, which is then followed by cooling and straining and when sufficient amount of cold water is passed through the drug, produces the desired volume [45].

\section{Percolation}

This technique is generally used for the extraction of active ingredients which was used for the preparation of tinctures and fluid extracts as well. A percolator is a narrow, cone-shaped vessel which has open at both the ends. The solid components are therefore moistened using a suitable quantity of menstruum and thereby allowing to stand aside for an approximate $4 \mathrm{~h}$ in a well tightly closed container, finally after all the mass has been packed, the percolator is closed at its top. Menstruum is added additionally above the mass as a shallow layer after which the mixture is allowed for maceration for $24 \mathrm{~h}$ in a closed percolator. The liquid which was contained in the percolator was let to drip off gradually from the outlet port. The liquid expressed was added to the percolator once the marc is pressed. Ample amount of menstruum is further added so as to produce the desired volume, finally, the liquid that is mixed is either clarified by filtration or by standing which then is followed by decanting [41].

\section{Sonication}

$20 \mathrm{kHz}$ to $2000 \mathrm{kHz}$ is the frequency range of the ultrasound employed for this method, extraction is done as a result of an increase in the permeability of cell wall and cavity formations [49,51]. Though the process is useful in certain extraction processes, its large-scale application is limited due to the higher costs. However, sonication has its own limitations such as deterioration of chosen compounds, resulting in the formation of free radicals which in turn results in a completely varied compound $[41,50,55]$.

\section{PHYTOCHEMICAL ASSAYS}

Assay for the detection of proteins and amino acids

Millon'stest: This test was performed by adding $2 \mathrm{ml}$ Millon's reagent to the extract which would form a white precipitate $[52,53]$. This on gently heating would turn red which indicates the presence of protein.

Xanthoproteic test: In this test, concentrated nitric acid was added dropwise to the extract. Presence of protein was confirmed when the solution turned yellow.

Ninhydrin test: This test when performed by adding $0.25 \%$ Ninhydrin reagent to the extract and boiled for few minutes forms blue color would confirm the presence of amino acids.

Table 1. Pharmacological actions of S. acmella

\begin{tabular}{|c|c|c|c|c|c|}
\hline S.No. & $\begin{array}{l}\text { Pharmacological } \\
\text { activity }\end{array}$ & Parts of plant used & Experimental models & Animals used & References \\
\hline 1. & Local anesthetic & Whole plant & $\begin{array}{l}\text { Intracutaneous wheal in guinea pigs and plexus } \\
\text { anesthesia in frog }\end{array}$ & Guinea pig, frog & [19] \\
\hline 2. & Antipyretic activity & Whole plant & Yeast-induced pyrexia & Albino rats & [19] \\
\hline 3. & $\begin{array}{l}\text { Anti-inflammatory } \\
\text { activity }\end{array}$ & The whole plant, leaves & Carrageenan-induced paw edema & Albino rats & {$[22,31]$} \\
\hline 4. & Analgesic activity & Whole plant & $\begin{array}{l}\text { Tail flick method, acetic acid-induced abdominal } \\
\text { constriction }\end{array}$ & Albino rats & [22] \\
\hline 5. & Antifungal activity & Flower & - & - & [23] \\
\hline 6. & Vasorelaxant activity & Flower & Partially endothelium induced nitric oxide and $\mathrm{PGI}_{2}$ & Albino rats & {$[30,31]$} \\
\hline 7. & Bioinsecticidal & Whole plant, leaves & - & - & {$[2,12,32]$} \\
\hline
\end{tabular}

Table 2: Solvents used for active component extraction

\begin{tabular}{|c|c|c|c|c|c|}
\hline Water & Ethanol & Methanol & Chloroform & Ether & Acetone \\
\hline Anthocyanins Starches & Tanins & Anthocyanins Tannins SaponinsTerpenoids & Terpenoids & Alkaloids & Flavonols \\
\hline Tannins Saponins & Polyphenols & Lactones & Flavonoids & Terpenoids & Phenols \\
\hline \multirow[t]{5}{*}{ Terpenoids Polypeptides Lectins } & Polyacetylenes & Flavones & & Coumarins & \\
\hline & Flavonols & Phenols & & Fatty acids & \\
\hline & Terpenoids & Polyphenols & & & \\
\hline & Sterols & & & & \\
\hline & Alkaloids & & & & \\
\hline
\end{tabular}


Assay for the detection of carbohydrates

Extracts were taken individually and diluted with distilled water and then filtered, which is further used for the assays [54,57].

Molisch's test: Violet ring formation was observed when alcoholic $\alpha$-naphthol reagent was added in drops to the extract in the test tube, this ring formation at the junction indicated the presence of carbohydrates.

Benedict's test: Orange-red precipitate formation indicated the presence of reducing sugars when Benedict's reagent was added to the extract.

Fehling's test: Brick red precipitate was formed at the bottom-most layer of the test tube when $2 \mathrm{ml}$ of Fehling A reagent and Fehling B reagent (which were added in equal quantities) to the extract obtained. This affirms that reducing sugars has its presence in the sample.

Iodine test: Addition of $2 \mathrm{ml}$ iodine solution to the extract produced either dark blue or purple colour. Therefore, the presence of carbohydrates has been affirmed.

\section{Assay for the detection of alkaloids}

To obtain the clarified extract, the extract was initially dissolved in dilute hydrochloric acid and filtered for assay purpose [56,59].

Mayer's Test: Addition of Mayer's reagent to the crude extract produced yellow coloured precipitate at the bottom indicating the presence of alkaloids.

Wagner's test: Wagner's reagent (iodine in potassium iodide) when added to the extract, produced brown/reddish precipitate at the bottom of the test tube which would indicate the presence of alkaloids.

Dragendroff's Test: Red precipitate formation was observed when Dragendroff's reagent was added to the extract, thus confirming the presence of alkaloids.

Hager's Test: Hager's reagent when treated with the extract produced yellow precipitate, thereby confirming the presence of alkaloids.

\section{Assay for the detection of glycosides}

Liebermann's test: A mixture of extract, $2 \mathrm{ml}$ of chloroform and acetic acid was taken and cooled by placing on ice. A color change from violet to blue and then gradually to green color was observed when concentrated sulfuric acid was added to the above mixture indicating the presence of glycone percentage of glycoside, i.e., steroidal nucleus.

Salkowski's test: Equal volumes of chloroform and concentrated sulfuric acid say $2 \mathrm{ml}$ each when mixed with the extract and shaken, produced reddish brown solution indicating the presence of glycone percentage of glycoside, i.e., steroidal nucleus.

Keller-kilani test: This test was performed by adding $2 \mathrm{ml}$ glacial acetic acid to the extract contained in a first test tube. (glacial acetic acid consisted 1-2 drops of $2 \%$ solution of $\mathrm{FeCl} 3$ solution). This mixture was further added to a second test tube containing concentration Sulfuric acid; therefore, cardiac glycoside presence was confirmed due to the formation of a brown ring.

\section{Assay for the detection of flavonoids}

Shinoda test: This test confirms the presence of flavonoids in the sample when pink scarlet's appeared in few minutes after the addition of magnesium ribbon fragments and careful addition of concentrated hydrochloric acid to the extract.

\section{Assay for the detection of saponins}

Saponin presence produced a stable foam when the extract was vigorously shaked with $5 \mathrm{ml}$ distilled water.
Assay for the detection of phenols

Ferric chloride test: The presence of phenols was indicated due to bluish black colour formation when 3-4 drops of ferric chloride were added to the extracts.

\section{Assay for the detection of tannins}

Gelatin test: Gelatin solution (1\%) containing sodium chloride when added to the extract produced white precipitate at the bottom of the test tube indicating the presence of tannins.

\section{Assay for the detection of diterpenes}

Copper acetate test: Copper acetate solution (3-4 drops) was added to the extracts which were dissolved in water, produced an emerald green color confirming the presence of diterpenes $[19,21,22]$.

\section{Assay for the detection of steroids}

For the detection of steroids, extract had been added with chloroform $(2 \mathrm{ml})$ and concentrated sulphuric acid was added along the sides. Steroid's presence was indicated due to the red color formation at the bottom-most layer.

\section{CONCLUSION}

S. acmella consists of several pharmacological actions, and a range of minor side effects is a familiar plant according to the Indian traditional system of medicine. In this current review, we have emphasized on ethnobotany, pharmacology, toxicology, phytochemistry plant material extraction procedure and phytochemical assays eloquently [59]. Phytoconstituent extracts from this plant species have shown to be effective in pharmacological responses such as anticonvulsant, antiinflammatory, analgesic, diuretic, vasodilation and antimalarial effects. Periodically researchers had been projecting that the entire plant notably has local anesthetic, anti-inflammatory, antioxidant, aphrodisiac, antinociception, immunomodulator and very importantly insecticidal effect. Similarly, lipase inhibition properties, diuretic [42], vasorelaxation, antifungal and pancreatic properties are the other noticeable activities, the flower part has been made known to produce. The pharmacological responses and the traditional usage of S. acmella have been listed in this review. Therefore it would give all the relevant scientific information concisely to the scientific society.

\section{CONFLICTS OF INTEREST}

The authors declare that there are no conflicts of interest.

\section{ACKNOWLEDGMENTS}

The authors are thankful to the Department Of Biotechnology and the management for providing guidance and support.

\section{REFERENCES}

1. Storey C, Salem JI. Lay use of Amazonian plants for the treatment of tuberculosis. Acta Amazonica 1997;27:175-82.

2. Sharma UK, Pegu S. Ethnobotany of religious and supernatural beliefs of the Mising tribes of Assam with special reference to the 'Dobur Uie'. J Ethnobiol Ethnomed 2011;7:1-13

3. Chung KF, Kono Y, Wang CM, Peng CI. "Notes on Acmella (Asteraceae): Helianthaceae in Taiwan. Bot Stud 2008;49:73-82.

4. Revathi P, Parimelazhghan T. Traditional knowledge on medicinal plants used by Irula tribe of Hasanur hills, Erode District, Tamil Nadu, India. Ethnobot Leaf 2010;14:136-60.

5. Vijendra N, Kumar KP. Traditional knowledge on ethno medicinal uses prevailing in tribal pockets of Chhindwara and Betul Districts, Madhya Pradesh, India. Afr J Pharm Pharmacol 2010;4:662-70.

6. Hossan MS, Hanif A, Agarwala B, Sarwar S, Karim M, Jahan R, et al. Traditional use of medicinal plants in Bangladesh to treat urinary tract infections and sexually transmitted diseases. Ethnobot Res Appl 2010;8:61-74.

7. Santesson CG. Several drugs of the Cameroon District and their native uses. Archi Furdie Bot A 1926;20:1-34.

8. Biswas A, Bari MA, Roy M, Bhadra SK. Inherited folk pharmaceutical 
knowledge of tribal people in the Chittagong hill tracts, Bangladesh. Indian J Tradit Knowl 2010;9:77-89.

9. Jondiko IJ. A mosquito larvicide in Spilanthes mauritiana. Phytochemistry 1986;25:2289-90.

10. Kadir HA, Zakaria MB, Kechil AA, Azirun MS. Toxicity and electrophysiological effects of Spilanthes acmella Murr. Pestic Sci 1989;25:329-35.

11. Mukharya DK, Ansari AH. Olean-12-en-3-O-beta-D-galactopyranosyl (1-4)-O-alpha-L-rhamnopyranoside: A new triterpenoidal saponin from the roots of Spilanthes. Indian J Chem Biol 1987;26:26-86.

12. Shelton AM, Wyman JA, Cushing NL, Apfelbeck K, Dennehy TJ, Mahr SE, et al. Insecticide resistance of diamondback moth, Plutella xylostella (Lepidoptera: Plutellidae), in North America. J Econ Entomol 1993;86:11-9.

13. Shelton AM, Robertson JL, Tang JD, Perez C, Eigenbrode SD, Preisler HK, et al. Resistance of diamondback moth (Lepidoptera: Plutellidae) to Bacillus thuringiensis subspecies in the field. J Econ Entomol 1993;86:697-705.

14. Verma DM, Balakrishnana NP, Dixit RD. Flora of Madhya Pradesh. Vol. 1. Kolkata: Botanical Survey of India; 1993. p. 612-3.

15. Gokhale VG, Bhide BV. Chemical Investigation of Spilanthes acmella. J Indian Chem Soc 1945;22:250-2.

16. Prachayasittikul S, Suphapong S, Worachartcheewan A, Lawung R, Ruchirawat S, Prachayasittikul V. Bio- active Metabolites from Spilanthes acmella Murr. Molecules 2009;14:850-67.

17. Martin R, Becker H. Spilanthol-related amides from Acmella ciliate. Phytochemistry 1984;23:1781-83.

18. Martin R, Becker H. Amides and Other constituents from Acmella ciliate. Phytochemistry 1985;24:2295-300.

19. Broussalis AM, Ferraro GE, Martino VS, Pin-Zon R, Coussio JD, Alvarez JC. Argentine plants as potential source of insecticidal compounds. J Ethnopharmacol 1999;67:219-23.

20. Pandey V, Agrawal V, Raghavendra K, Dash AP. Strong insecticidal activity of three species of Spilanthes (Akarkara) against Malaria (Anopheles stephensi Liston, Anopheles culicifacies, species C) and Filaria Vector (Culex quinquefasciatus Say). Parasitol Res 2007;102:171-4.

21. Ramsewak RS, Erickson AJ, Nair MG. Bioactive N-isobutylamides from the flower buds of Spilanthes acmella. Phytochemistry 1999;51:729-32

22. Okemo P, Ansorg R. Activity of east african medicinal plants against Helicobacter pylori. Chemother Basel 1996;42:315-7.

23. Rani SA, Murty SU. Evaluation of antimicrobial activity of Spilanthes acmella flower head extract. J Nat Remedies 2005;5:170-1.

24. Sharma GV, Shekharam T, Upender V. Stere- oconvergent synthesis of a potent mosquito larvicide: (2E,4E,8E,10Z)-N-(2-methylprpyl)2,4,8,10-dodecatetraeneamide. Tetrahedron 1990;46:5665-72.

25. Fabry W, Okemo P, Ansorg R. Fungistatic and fungicidal activity of east African medicinal plants. Mycoses 1996;39:67-70

26. Rai MK, Verma A, Pandey AK. Antifungal activity of Spilanthes calva after inoculation of Pirifor-maspora indica. Mycoses 2002;47:479-81.

27. Phongpaichit S, Subhadhirasakul S, Wattanapi-Romsakul C. Antifungal activities of extracts from Thai medicinal plants against opportunistic fungal pathogens associated with AIDS Patients. Mycoses 2005;48:333-8.

28. Rani SA, Murty SU. Antifungal potential of flower head extract of Spilanthes acmella Linn. Afr J Biomed Res 2006;9:67-8.

29. Okwu DE. Phytochemicals and vitamin content of indigenous species of southeastern Nigeria. J Sustain Agric Environ 2004;6:30-7.

30. Just MJ, Recio MC, Giner RM, Cueller MU, Manez S, Billia AR, et al. Antiinflammatory activity of unusual lupine saponins from Bupleurum fruticescens. Planta Med 1998;64:404-7.

31. Sodipo OA, Akiniyi JA, Ogunbamosu JU. Studies on certain on certain characteristics of extracts of bark of Pansinystalia macruceras (K schemp) picrre Exbeille. Glob J Pure Appl Sci 2000;6:83-7.

32. Raquel FE. Bacterial lipid composition and antimicrobial efficacy of cationic steroid coppounds. Biochem Biophys Acta 2007;1768:2500-9.

33. Okwu DE. Evaluation of chemical composition of medicinal plants belonging to Euphorbiaceae. Pak Vet J 2001;14:160-2.

34. Nobori T, Miurak K, Wu DJ, Takabayashik LA, Carson DA. Deletion of cyclin-dependent kinase-4 inhibitor gene in multiple human cancers. Nature 1994;46:753-6.

35. Antherden LM. Textbook of Pharmaceutical Chemistry. $8^{\text {th }}$ ed. London: Oxford University Press; 1969. p. 813-4.

36. Stray F. The Natural Guide to Medicinal Herbs and Plants. London: Tiger Books International; 1998. p. 12-6.

37. Okwu DE, Okwu ME. Chemical composition of Spondias mombin linn. Plant parts. J Sustain Agric Environ 2004;6:140-7.

38. Nyarko AA, Addy ME. Effects of aqueous extract of Adenia cissampeloides on blood pressure and serum analyte of hypertensive patients. Phytother Res 1990;4:25-8.

39. Ahmad I, Mehmood Z, Mohammad P, Ahmed S. Antimicrobial potency and synergistic activity of five traditionally used Indian medicinal plants. J Med Arom Plant Sci 2000;22:173-6.

40. Darokar MP, Mathur A, Dwivedi S, Bhalla R, Kanuja SP, Kumar S. Detection of antibacterial in the floral petals of some higher plants. Curr Sci 1998;75:187-9.

41. Fabry W, Okemo PO, Ausorg R. Antibacterial activity of east african medicinal plants. J Ethnopharmocol 1998;60:19-24

42. Rajesh Y, Nita Y, Murli DK, Rudraprabhu S. Preliminary studies on diuretic effect of Spilanthes acmella leaves extracts in rats. Int J Pharm Pharm Sci 2011;3:245-7.

43. Sahaya S, Servin W, Devi BC. Antimicrobial activity of in vitro raised Acmella calva (DC.). Int J Pharm Pharm Sci 2012;4 Suppl 5;124-7.

44. Sharma J, Boonen NS, Chauhan M, Thakur B, De Spiegeleer B, Dixit VK. Spilanthes acmella ethanolic flower extract: LC-MS alkylamide profiling and its effects on sexual behavior in male rats. Phytomedicine 2011;18:1161-9.

45. Parekh J, Karathia N, Chanda S. Evaluation of antibacterial activity and phytochemical analysis of Bauhinia variegata L. Bark. Afr J Biomed Res 2006;9:53-6.

46. Remington JP. Remington: The Science and Practice of Pharmacy. $21^{\text {st }}$ ed. Philadelphia, PA: Lippincott Williams and Wilkins; 2005. p. 773-4.

47. Roopashree TS, Dang R, Rani SR, Narendra C. Antibacterial activity of anti- psoriatic herbs: Cassia tora, Momordica charantia and Calendula officinalis. Int J Appl Res Nat Prod 2008;1:20-8.

48. Sutar N, Garai R, Sharma US, Sharma UK. Anthelmintic activity of Platycladus orientalis leaves extract. Int J Parasitol Res 2010;2:1-3.

49. Sharma US, Sharma UK, Singh A, Sutar N, Singh PJ. In vitro anthelmintic activity of Murraya koenigii linn. Leaves extracts. Int J Pharm Biosci 2010;1:1-4.

50. Vidyadhar S, Saidulu M, Gopal TK, Chamundeeswari D, Rao U, Banji D. In vitro anthelmintic activity of the whole plant of Enicostemma littorale by using various extracts. Int J Appl Biol Pharm Technol 2010;1:1119-25.

51. Wallis TE. Text Book of Pharmacognosy. New Delhi: CBS Publishers and Distributors; 1989. p. 356-549.

52. Wang GX, Han J, Zhao LW, Jiang DX, Liu YT, Liu XL, et al. Anthelmintic activity of steroidal saponins from Paris polyphylla. Phytomedicine 2010;17:1102-5.

53. Wang GX, Zhou Z, Jiang DX, Han J, Wang JF, Zhao LW, et al. In vivo anthelmintic activity of five alkaloids from Macleaya microcarpa (Maxim) fedde against dactylogyrus intermedius in Carassius auratus. Vet Parasitol 2010;171:305-13.

54. Eloff JN. Which extractant should be used for the screening and isolation of antimicrobial components from plants? J Ethnopharmacol 1998;60:1-8.

55. Evans WC. Treas and Evans "Pharmacognosy." $14^{\text {th }}$ ed. Edinburgh: WB Saunders Company Ltd.; 2002. p. 3-4.

56. Handa SS, Khanuja SP, Longo G, Rakesh DD. Extraction Technologies for Medicinal and Aromatic Plants. Trieste: International Centre for Science and High Technology; 2008. p. 21-5.

57. Johansen DA. Plant Micro Technique. New York: McGraw Hill Book Co.; 1940. p. 182-97.

58. Rai MK, Acharya D. Screening of some Asteraceous plants for antimycotic activity. Composit Newslett 1999;34:37-43

59. Rai MK, Varma A, Pandey AK. Antifungal potential of Spilanthes calva after inoculation of Piriformospora indica. Mycoses 2004;47:479. 